\title{
Development of quality metrics for ambulatory care in pediatric patients with tetralogy of Fallot
}

\author{
Juan Villafane MD, FACC ${ }^{1}$ (1) | Thomas C. Edwards MD, FACC2 \\ Karim A. Diab MD, FACC ${ }^{3}$ | Gary M. Satou MD ${ }^{4}$ | Elizabeth Saarel MD, FACC 5 । \\ Wyman W. Lai MD, MPH, FACC 6 | Gerald A. Serwer MD7 | \\ Peter P. Karpawich MD, FACC ${ }^{8}$ | Russell Cross MD, FACC ${ }^{9}$ । \\ Russell Schiff MD, FACC10 | Devyani Chowdhury MD, FACC11 | \\ Thomas J. Hougen MD, FACC ${ }^{12}$
}

${ }^{1}$ Department of Pediatrics (Cardiology), University of Kentucky, Lexington, Kentucky, USA

${ }^{2}$ Department of Pediatric Cardiology, University of Central Florida, Orlando, Florida, USA

${ }^{3}$ Department of Pediatric Cardiology, Rush University Medical Center, Chicago, Illinois, USA

${ }^{4}$ Department of Pediatric Cardiology, David Geffen School of Medicine at UCLA, Los Angeles, California, USA

${ }^{5}$ Department of Pediatric Cardiology, Cleveland Clinic Foundation, Cleveland, Ohio, USA

${ }^{6}$ Division of Pediatric Cardiology, Children's Hospital of Orange County, Orange, California, USA

${ }^{7}$ Department of Pediatric Cardiology, University of Michigan Health System, Ann Arbor, Michigan, USA

${ }^{8}$ Department of Pediatric Cardiology, Wayne State University School of Medicine, Detroit, Michigan, USA

${ }^{9}$ Department of Pediatric Cardiology, George Washington University, Washington, DC, USA

${ }^{10}$ Department of Pediatric Cardiology, Cohen Children's Medical Center of New York, Queens, New York, USA

${ }^{11}$ Cardiology Care for Children, Lancaster, Pennsylvania, USA

${ }^{12}$ Department of Cardiology, Children's National Heart Institute, Arlington, Virginia, USA

\section{Correspondence}

Juan Villafane, 743 East Broadway, Suite 300, Louisville, KY 40202.

Email: juanvillaf@yahoo.com

\begin{abstract}
Objective: The objective of this study was to develop quality metrics (QMs) relating to the ambulatory care of children after complete repair of tetralogy of Fallot (TOF).

Design: A workgroup team (WT) of pediatric cardiologists with expertise in all aspects of ambulatory cardiac management was formed at the request of the American College of Cardiology (ACC) and the Adult Congenital and Pediatric Cardiology Council (ACPC), to review published guidelines and consensus data relating to the ambulatory care of repaired TOF patients under the age of 18 years. A set of quality metrics (QMs) was proposed by the WT. The metrics went through a twostep evaluation process. In the first step, the RAND-UCLA modified Delphi methodology was employed and the metrics were voted on feasibility and validity by an expert panel. In the second step, QMs were put through an "open comments" process where feedback was provided by the ACPC members. The final QMs were approved by the ACPC council.
\end{abstract}

Results: The TOF WT formulated 9 QMs of which only 6 were submitted to the expert panel; 3 QMs passed the modified RAND-UCLA and went through the "open comments" process. Based on the feedback through the open comment process, only 1 metric was finally approved by the ACPC council.

Conclusions: The ACPC Council was able to develop QM for ambulatory care of children with repaired TOF. These patients should have documented genetic testing for $22 q 11.2$ deletion. However, lack of evidence in the literature made it a challenge to formulate other evidence-based QMs.

KEYWORDS

congenital heart disease, pediatric cardiology, quality metrics, tetralogy of Fallot 


\section{INTRODUCTION}

Tetralogy of Fallot (TOF) is the most common cyanotic heart defect accounting for $7 \%-10 \%$ of all congenital heart defects (CHD). Although the surgical mortality is low, there still exists significant morbidity during mid- and long-term follow-up. Optimal longitudinal ambulatory care is essential and should focus on preventing any complications after TOF surgical repair ${ }^{1,2}$ and quality of life for the patients.

The imperative to develop ambulatory QMs (QMs) is based on the recognition that the number of children with CHD successfully treated is rapidly increasing and they face new challenges as they age. ${ }^{3}$ Very few guidelines for the outpatient management of patients with $\mathrm{CHD}$ are available. $^{4-6}$ The American College of Cardiology (ACC) has developed several clinical performance measures to evaluate quality of care, to stimulate quality improvement, and to test the effectiveness of interventions provided. ${ }^{7-9}$ However, until now, standardized quality indicators for the outpatient management of pediatric patients with repaired TOF have not been developed. QMs can address issues related to optimal medical management. This paper demonstrates the development of QMs and key issues that surfaced during the process.

\section{2 | METHODS}

\section{1 | Scope of project}

A subcommittee of the ACC Adult Congenital and Pediatric Cardiology Council (ACPC) sought to develop several QMs that would indicate best practice in outpatient care of pediatric patients after repair of uncomplicated TOF. The task of the working team (WT) was to create quality metrics that would help to improve patient outcome and decrease practice variation by standardizing care of these patients. ${ }^{7}$

\section{2 | Work process}

The WT consisted of 11 pediatric cardiologists, including a team leader. This group met at regular intervals to: (1) discuss the scope of the project; (2) define the study population in an ambulatory setting; and (3) perform a literature search including any relevant practice guidelines that help formulate candidate quality-of-care indicators. The WT was then divided into smaller groups of 2-3 WT members to review most aspects of ambulatory care for pediatric patients with repaired TOF. A total of 9 QMs were originally proposed by the entire team (Table 1). Three of the QMs were eliminated by the WT after feedback from ACC ACPC QM steering committee chairs. The remaining six QMs were submitted for voting by an expert panel formulated by representation from 9 national and international CHD organizations. QMs were analyzed for clinical relevance, ease of measurement, and feasibility for widespread application. Three metrics passed the RAND ${ }^{10}$ process; however, only one of these 6 QMs passed the "open comments" and received final approval by the ACPC. These and other QMs for pediatric ambulatory care were recently published. ${ }^{11}$

\section{3 | RESULTS}

\section{1 | Literature review}

No uniform approach exists for the postoperative ambulatory care of children with TOF in part, due to: (1) absence of longitudinal studies in this age group and (2) variability of the outpatient management from institution to institution. Wernovsky et al., provided a framework for outpatient follow-up of complex CHD based on a review of published literature, the experience of a single academic center, and a national quality improvement collaboration. ${ }^{12,13}$ A group from Cincinnati Children's Hospital Medical Center developed a set of recommendations for follow-up of TOF patients. Their recommendations have been added to the national guidelines clearing house database. ${ }^{14}$ The Cincinnati group developed most of their recommendations by way of consensus

TABLE 1 Quality metrics for outpatients with uncomplicated tetralogy of Fallot

\begin{tabular}{|c|c|}
\hline Scope of metrics & Quality metric numerator ${ }^{a}$ \\
\hline Cardiac catheterization ${ }^{\mathrm{b}}$ & Cardiac catheterization for significant residual defect, ventricular dysfunction or cyanosis \\
\hline Surgical report ${ }^{\mathrm{b}}$ & Report present in medical record at initial postoperative visit \\
\hline Exercise testing ${ }^{b}$ & $\geq 1$ exercise test between 10 and 18 years of age \\
\hline Timing of postoperative outpatient visits ${ }^{c}$ & Repaired TOF patients with at least 1 outpatient cardiology visit in the past 15 months \\
\hline Electrocardiographic testing ${ }^{c}$ & All postoperative TOF patients with a least 1 ECG in the past 15 months \\
\hline Ambulatory electrocardiographic monitoring ${ }^{c}$ & At least 1 Holter performed over the past 5 years \\
\hline Echocardiographyc & Annual echocardiogram in the past 15 months \\
\hline Magnetic resonance imaging ${ }^{b}$ & $\geq 1$ cardiac MRI between 8 and 18 years of age \\
\hline Genetic testing ${ }^{c}$ & Patients should have documented genetic testing for $22 \mathrm{q} 11.2$ deletion \\
\hline
\end{tabular}

${ }^{a}$ Denominator for all metrics: all postoperative tetralogy of Fallot outpatients.

${ }^{\text {b}}$ Three metrics eliminated by work team.

${ }^{\mathrm{c}} \mathrm{Six}$ metrics were rated by an expert panel on validity ${ }^{1-9}$ and feasibility. ${ }^{1-9}$

Only genetic testing was approved. 
since the body of evidence supporting most of their recommendations was considered "low quality." Follow-up indicators included annual office visits, ECG, and annual echocardiograms at least through 10 years of age. Chest $x$-rays, cardiac magnetic resonance imaging (MRI), exercise testing, and ambulatory ECG monitoring were recommended at longer time intervals. The guidelines from the ACC/American Heart Association (AHA) 2008 and the European Society of Cardiology (ESC) 2010 for the management of adults with CHD were used by the WT as a resource in formulating the QMs. ${ }^{5,6} \mathrm{~A}$ few published articles on QMs in pediatric cardiology that were applicable to this project were reviewed by the WT. ${ }^{7-9,15}$

\section{2 | Proposed quality metrics}

Following several WT meetings, 9 candidate QMs were defined based on feasibility and reliability of data as well as potential impact on the specific QM in patient outcome.

\subsubsection{Timing of outpatient visits after corrective surgery}

This QM was based on the WT consensus as there was no specific standard on the timing of postoperative outpatient visits for TOF pediatric patients, especially during infancy. The ACC/AHA 2008 and other guidelines recommended at least annual follow-up for older patients with TOF. ${ }^{5,6,12-14,16}$ This QM failed to be approved due to insufficient scientific data to support specific timing intervals for follow-up visits. Postoperative TOF patients have different severity of defects, and types of surgical procedures, for example, infundibular muscle resection with VSD closure versus a transannular patch. Therefore, some patients may require being seen less frequently than others.

\subsubsection{Echocardiography}

A two-dimensional and Doppler echocardiogram provides a useful noninvasive method for the detection of residual lesions as well as assessment of right ventricular size, systolic pressure and function and LV function. Serial measurements may also be helpful in monitoring the progression of any residual lesions. The timing of such evaluations is the subject of much debate with no consensus on the frequency of follow-up testing. Although there is no conclusive evidence to adopt the use of annual echocardiography as a QM, the WT reached a consensus of a yearly study during follow-up. ${ }^{5,17}$ Echocardiographic testing should enable better patient management following repair of TOF and can be helpful in determining the need for additional testing such as cardiac catheterization or MRI.

\subsection{3 $\mid \mathrm{MRI}$}

The right ventricle (RV) and great arteries become difficult to evaluate by echocardiography in older patients with increasing body size. MRI correlates well with clinical status and has been the reference standard for evaluating the RV, particularly with regard to timing of pulmonary valve replacement. The indication and timing for pulmonary valve replacement remains controversial and makes appropriate timing of imaging difficult to establish., ${ }^{5,-20}$

\subsection{4 | Cardiac catheterization}

Diagnostic catheter-based studies for children following repair of TOF are rarely necessary. In many instances, the combination of highquality echocardiography and cardiac MRI/CT will adequately define residual lesions of concern. However, some patients will benefit from cardiac catheterization, especially if transcatheter intervention is likely. Examples include quantifying residual shunts, assessing difficult-toimage (via echocardiogram) branch pulmonary artery anatomy, and determining ventricular function and hemodynamics. Therapeutic intervention such as pulmonary artery angioplasty and stenting may also be provided. This QM was eliminated by the WT because of low feasibility rating and lack of current support in the literature.

\subsection{5 | Surgical report}

A postoperative report and discharge summary should be available at the first postsurgical clinic visit. If a written report is not available, at minimum, a documentation of personal communication between the inpatient care team and the outpatient cardiologist should be available. The receipt of timely intraoperative reports and postoperative recovery history by the office-based cardiologist is essential to improve transition of care from inpatient to outpatient. Particular events prior to discharge may alert the outpatient team to areas of concern that may need added scrutiny. Examples include residual anatomic defects, ventricular dysfunction, history of postoperative arrhythmias and, at times, psychological issues. Similarly, it is important for the outpatient team to provide the hospital cardiovascular surgical team with data on the discharged patients. These reports constitute a method of adding to the surgical results database required for outcome analysis. This QM was eliminated from consideration because it did not meet operational standards and could not be supported by any relevant literature.

\subsection{6 | Exercise testing}

Patients with repaired TOF are at long-term risk for exercise intolerance, arrhythmias, and sudden death due to residual defects, progressive right and left ventricular dysfunction and myocardial scarring. Cardiopulmonary exercise testing provides a noninvasive method of quantifying cardiac and pulmonary limitations and may help with risk stratification of arrhythmias and sudden cardiac death. Serial measurements are helpful in quantifying functional status and risk progression over time. Existing guidelines have endorsed the use of exercise testing for follow-up of children and adults with TOF after repair., ${ }^{5,6}$ Because there is no established criteria for the timing and frequency of exercise testing as a QM in pediatric TOF, the WT eliminated this QM before submission to the expert panel.

\subsection{7 | ECG testing}

Patients with repaired TOF remain at risk for sudden death; 1.5 to 4.5 deaths per 1000 patients-years at 4 or more years after repair. ${ }^{21}$ Studies have reported that prolongation of the QRS is considered to be a risk factor for sudden death. ${ }^{22}$ Rarely, late onset heart block has been reported. In spite of a therapeutic shift to primary intracardiac repair at an early age, damage to the cardiac conduction system may contribute to patient morbidity and mortality. A routine ECG screening remains a 
viable and simple test to evaluate any progressive changes in conduction such as increasing PR interval and QRS duration, and may act as a marker for any change in RV volume frequently associated with pulmonary regurgitation. ${ }^{23}$ However, limited evidence exists regarding the frequency of ECG testing in this setting.

\subsubsection{Ambulatory ECG monitoring (Holter)}

Ambulatory ECG monitoring can detect ECG or rhythm disorders in asymptomatic patients. Among the patients in whom arrhythmias do occur and who require therapy, this test helps in therapeutic decision making. There is no published data to determine frequency of monitoring. $5,12,24$

\subsection{9 | Genetic testing}

Systematic determination of potential long-standing support for discovering the underlying genetic causes of $\mathrm{CHD}$ has been advocated by the ACC, AHA, and the American Academy of Pediatrics. ${ }^{25}$ Genetic testing might shed light on other system involvement that may provide prognostic information regarding CHD and other organ systems. It facilitates counseling regarding recurrence risks and helps to identify other family members who would benefit from genetic testing. Patients with TOF demonstrate associated genetic syndromes or chromosome abnormalities in approximately $25 \%$ of cases. In over $15 \%$ of cases, a 22q11.2 deletion is found. ${ }^{26-28}$ Hence, it is logical to encourage genetic screening for all of these patients. The ACC and AHA guidelines for the management of adults with CHD have called for screening for 22q11 deletion in patients with TOF. ${ }^{5}$ Similarly, the Canadian Cardiovascular Society Consensus Conference guidelines on management of adults with CHD recommended testing for 22q11 deletion in all patients with TOF. ${ }^{17}$ Although there is still some debate whether or not all TOF patients should be tested for $22 \mathrm{q} 11$ deletion, the WT concluded that there should be no exception. At least $6 \%$ of TOF patients without arch anomalies have a 22q11 deletion. ${ }^{29}$ Clinical assessment for dysmorphic signs of 22q11 may be subtle and difficult to identify, especially in infants. ${ }^{30,31}$ Hence, the current QM results in the early detection of 22q11 deletion in affected TOF patients. Moreover, there is literature describing an increase in mortality risk in patients who have this genetic abnormality. ${ }^{32,33}$

\section{4 | DISCUSSION}

The goals of the WT were to develop QMs that would: (1) improve clinical outcomes for postoperative TOF pediatric patients; (2) decrease variation in practice patterns; and (3) avoid underuse of vital tests. The whole process led to approval of $1 \mathrm{QM}$, genetic testing, for outpatient management of pediatric TOF patients after surgical repair. These patients should have documented genetic testing for 22q11.2 deletion.

The development and implementation of QMs intended to guide the practitioner to assess specific areas in children with repaired TOF present unique challenges primarily due to variable anatomy, and changing surgical and interventional techniques that may influence long term outcomes.
There were several other challenges that the WT encountered: (1) lack of standardized quality care ${ }^{34,35}$ in outpatient management of pediatric patients with TOF; (2) lack of long-term prospective studies; and (3) current guidelines are based mostly on consensus or low levels of evidence. The WT was invited by ACC/ACPC to design several QMs for postoperative TOF patients from the neonate to 18 years of age. Essential features of the selected QMs candidates included: (1) ease of measuring accurately; (2) clearly identifiable data that is easy to retrieve for analysis; and (3) available scientific evidence to define quality of care.

A guideline from the American Society of Echocardiography, published in 2014, on multimodality imaging of repaired TOF patients recommended echocardiography for routine surveillance annually until the age of 10 , and then every two years afterwards as a class IC recommendation. ${ }^{36}$ The same document recommended cardiac MRI testing every 36 months beginning at the age of 10 years in stable patients and annually in cases of moderate or progressive RV dilation and/or $\mathrm{RV}$ dysfunction. This specific document was published after submission of candidate QM on MRI and echocardiography by the WT to the Expert Panel. The testing intervals proposed by the WT on these two QM differed slightly from the 2014 guideline. This publication was available for review during the open comment period and hence was used as a reference. To respect the input from the community and to give credence to this process, the echocardiography and MRI metrics were rejected due to the inability to adopt the newly recommended testing intervals.

The WT experience along with the thoughtful feedback from the ACC/ACPC committee emphasized the need for ongoing efforts to develop QMs for the young patients with surgically repaired CHD. TOF presented particular challenges to define QMs in part because of the lack of widely established guidelines that met the study criteria. Nevertheless, although these data is lacking, it should not deter efforts to acquire this vital information. Consensus expert opinion is often the usual method deciding what type and when an evaluation or intervention should be done. However, until QM data are acquired, physicians will only know what is currently practiced and not what evidencebased criteria indicate.

In conclusion, the creation of QMs for outpatient care of TOF pediatric patients after surgical repair would help enhance the care provided and limit the degree of variation adopted by various practices or institutions. Hence, the objective is that these QMs will be a useful guide for quality improvement. It would be important to further test these QMs and their impact on improving clinical outcomes in this patient population.

\section{CONFLICT OF INTEREST}

None.

\section{AUTHOR CONTRIBUTIONS}

Writing Team (WT) contributions-Participation by each co-author: Co-coordinator for meetings and design of project; literature search/ review; contributed to EP-related sections, preparation of drafts and final manuscript: Juan Villafañe 
Help with research and manuscript (writing and editing): Thomas Edwards

In charge of echo section and genetics; review and editing of manuscript: Karim Diab

Participation and discussion in development of project; contributor to echo and all imaging sections; manuscript review: Gary Satou.

Literature search and review; contributed to ambulatory ECG monitoring, ECG and exercise testing; revision and editing of manuscript: Elizabeth Saarel

In charge of echo and MRI; literature search: Wyman W. Lai

Formulation of ECG section; review of draft and final version of the manuscript: Gerald A. Serwer

Help in EP-related sections and literature search: Peter Karpawich

Help developing project and manuscript review and editing: Russell Cross

Help designing project and participated in all conference calls: Russell Schiff

Co-coordinator and liaison with expert panels: Devyani Chowdhury

WT leader, contributed to surgical reports, preparation of drafts and final document: Tom Hougen

NOTE: All co-authors attended regular meetings.

\section{ORCID}

Juan Villafane MD, FACC (D) http://orcid.org/0000-0003-2901-8338

\section{REFERENCES}

[1] Lannon CM, Peterson LE. Pediatric collaborative networks for quality improvements and research. Acad Pediatr. 2013;13(suppl 6): S69-S74.

[2] Moller $\mathrm{JH}$. Using data to improve quality: the pediatric cardiac care consortium. Congenit Heart Dis. 2016;11:19-25.

[3] Said SM, Driscoll DJ, Dearani JA. Transition of care in congenital heart disease from pediatrics to adulthood. Semin Pediatr Surg. 2015;24:69-72.

[4] Villafane J, Feinstein JA, Jenkins KJ, et al. Hot topics in tetralogy of Fallot. J Am Coll Cardiol. 2013;62:1-12.

[5] Warnes CA, Williams RG, Bashore TM, et al. ACC/AHA guidelines for the management of adults with congenital heart disease. J Am Coll Cardiol. 2008;52:143-263.

[6] Baumgartner $\mathrm{H}$, Bonhoeffer P, DeGroog NMS, et al. ESC guidelines for the management of grownup congenital heart disease (new version 2010). Eur Heart J. 2010;31:2915-2957.

[7] Spertus JA, Eagle KA, Krumolz HM, et al. American College of Cardiology and American Heart Association methodology for the selection and creation of performance measures for quality for quantifying the quality of cardiovascular care. J Am Coll Cardiol. 2005;3:1147-1156.

[8] Bonow RO, Mascudi FA, Rumsfeld JS, et al. ACC/AHA classification of care metrics: performance measures and quality metrics. J Am Coll Cardiol. 2008;52:2113-2117.

[9] Spertus JA, Bonow RO, Chan B, et al. ACC/AHA new insights into methodology of performance measurement. Circulation. 2010;122: 2091-2106.
[10] Normand SL, McNeil BJ, Peterson LE, Palmer RH. Eliciting expert opinion using the Delphi technique: identifying performance indicators for cardiovascular disease. Int J Qual Health Care. 1998;10(3):247-260.

[11] Chowdhury D, Gurvitz M, Marelli A, et al. Development of quality metrics in ambulatory Pediatric Cardiology. J Am Coll Cardiol. 2017; 69:541-555.

[12] Wernovsky G, Rom JJ, Tabbutt S, et al. Guidelines for the outpatient management of complex congenital heart disease. Congenit Heart Dis. 2006;1:10-26.

[13] Wernovsky G, Lihn SL, Olen MM. Creating a lesion-specific "road map" for ambulatory care following surgery for complex congenital heart disease. Cardiol Young. 2017;27:648-662.

[14] ACC/AHA 2008 guidelines for the management of adults with congenital heart disease. Report of the ACC/AHA task force on practice guidelines. American College of Cardiology Foundation. American Heart Association. NGC:007068.

[15] Jacobs JP, Jacobs ML, Austin EH, et al. Quality measures for congenital and pediatric cardiac surgery. World J Pediatric and Congenit Heart Surg. 2012;3:32-47.

[16] Geva T. Indications and timing of pulmonary valve replacement after tetralogy of Fallot surgery. Thorac Cardiovascular Surg, Pediatr Cardiac Surg Ann. 2006;9:11-22.

[17] Silversides CK, Kiess $M$, Beauchesne L, et al. Canadian cardiovascular society 2009 consensus conference on the management of adults with congenital heart disease: outflow tract obstruction, coarctation of the aorta. tetralogy of Fallot, Ebstein anomaly and Marfan's syndrome. Can J Cardiol. 2010;26:142-150.

[18] Hundley WG, Bluemke D, Finn JP, et al. ACC-ACR-AHA-NASCVSMR 2010 Expert consensus document on cardiovascular magnetic resonance. A report of the American Cardiology Foundation task force on expert consensus documents. Circulation. 2010;121:246-508.

[19] Kilner PJ, Geva T, Kaemmerer H, et al. Recommendations for cardiovascular magnetic resonance in adults with congenital heart disease from the respective working groups of the European society of Cardiology. Eur Heart J. 2010;31:794-805.

[20] Geva T. Repaired tetralogy of Fallot: the roles of Cardiovascular magnetic resonance in evaluating pathophysiology and for pulmonary valve replacement decision support. J Cardiovasc Magn Reson. 2011;13:9

[21] Arya S, Kovach J, Singh $\mathrm{H}$, et al. Arrhythmias and sudden death among older children and young adults following tetralogy of Fallot repair in the current era: are previously reported risk factors still applicable? Congenit Heart Dis. 2014;9:407-423.

[22] Gatzoulis MA, Till J, Somerville J, et al. Mechanoelectrical interaction in tetralogy of Fallot: QRS prolongation relates to right ventricular size and predicts malignant ventricular arrhythmias and sudden death. Circulation. 1995;92:231-237.

[23] Massin MM, Malekzadeh-Milani SG, Schlffler S, et al. Long-term electrocardiographic follow-up after repair of tetralogy of Fallot. Ann Noninvasive Electrocardiol. 2011;16:336-343.

[24] Czosek RJ, Anderson J, Khoury PR, et al. Utility of ambulatory monitoring patients with congenital heart disease. Am J Cardiol. 2013; 111:723-730.

[25] Pierpont ME, Basson CT, Benson DW Jr. Genetics of congenital heart defects: current knowledge: a scientific statement from the American Heart Association Council cardiovascular disease in the young. Circulation. 2007;11:3015-3038.

[26] Momma K, Takao A, Matsuoka R, et al. Tetralogy of Fallot associated with chromosome 22q, 11.2 deletion in adolescents and young adults. Genet Med. 2001;3:56-60. 
[27] Fahed AC, Gelb BD, Seidman JG, Seidman CE. Genetics of congenital heart disease: the glass half empty. Circ Res. 2013;112:707-720.

[28] Goldmuntz E. DiGeorge syndrome: new insights. Clin Perinatol. 2005;32:963-978.

[29] Goldmuntz E, Clark BJ, Mitchell E, et al. Frequency of 22q11 deletions in patients with conotruncal defects. J Am Coll Cardiol. 1998; 32:492-498.

[30] Digillio MC, Angioni A, De Santis M, et al. Spectrum of clinic variability and familial deletion 22q11.2 from full manifestation to extremely mild clinical anomalies. Clin Genet. 2003;63:308-313.

[31] Amati F, Mari A, Digillo MC, et al. 22q11 deletions in isolated and syndromic patients with tetralogy of Fallot. Hum Genet. 1995;95: 479-482.

[32] Anaclerio S, Di C, Michielon G, et al. Conotruncal heart defects: impact of genetic syndromes on immediate operative mortality. Ital Heart J. 2004;5:624-628.

[33] Connor JA, Hinton RB, Miller EM, et al. Genetic testing practices in infants with congenital heart disease. Congenit Heart Dis. 2014;9: 158-167.
[34] Farias M, Jenkins K, Lock J, et al. Standardized clinical assessment and management plans (SCAMPs) provides a better alternative to clinical practice guidelines. Health Affairs. 2013;32:911-920.

[35] Friedman KG, Rathod RH, Farias M, et al. Resource utilization after introduction of a standardized clinical assessment and management plan. Congenit Heart Dis. 2010;5:374-381.

[36] Valente AM, Cook S, Festa P, et al. Multi-modality imaging guidelines for patients with repaired tetralogy of Fallot: report from the American society of echocardiography: developed in collaboration with society for cardiovascular magnetic resonance and this society of pediatric radiology. J Am Soc Echocardiogr. 2014;27:111-141.

How to cite this article: Villafane J, Edwards TC, Diab KA, et al. Development of quality metrics for ambulatory care in pediatric patients with tetralogy of Fallot. Congenital Heart Disease. 2017;12:762-767. https://doi.org/10.1111/chd.12523 